Jiang, FK. \& Hyland, K. (2021). "The goal of this analysis ...”: Changing patterns of metadiscursive nouns in disciplinary writing. Lingua.

https://www.sciencedirect.com/science/article/pii/S0024384120302254

\title{
"The goal of this analysis ...": Changing patterns of metadiscursive nouns in disciplinary writing
}

\begin{abstract}
The last 50 years have seen considerable changes in both research and publication practices in international English-medium arenas, and also witnessed a shift in argument styles in academic texts over these years (e.g. Hyland \& Jiang, 2019). However, little attention was given to the rhetorical roles of nouns in diachronic studies of professional research writing. This is surprising since academic writing is an extremely noun-heavy register and novice writers often find nominal expressions difficult. In this study, we examine what are called metadiscursive nouns, a type of unspecific abstract nouns, in our diachronic corpus of disciplinary research writing to see whether they have increased in recent decades. It is found that this $N$ pattern is most frequent overall, but hard scientists made increased use of quality nouns to promote the value of their research outcome while writers in the soft disciplines prefer evidential nouns for factual support to their knowledge claims. All these point to the need to include metadiscursive nouns into the rhetorical repertoire of metadiscourse and to emphasise their functions in the course of using English for research and publication purposes.
\end{abstract}

Keywords: metadiscursive nouns; disciplinary writing; diachronic changes; textual interaction; academic persuasion 


\section{Introduction}

While sometimes considered an invariant, unchanging form of discourse, published academic writing is very much a product of its times and as a result, diachronic investigations help illuminate some of the changes in discursive practice. Atkinson (1999), for instance, has identified a steady trend towards a less narrative-oriented and more abstract form of presentation in science writing during the 18th and 19th centuries as research became a more professional and empirical activity. More recently, Hyland \& Jiang (2019) have noted a shift away from explicit markers of stance and authorial attitude and toward greater writer presence as writers seek to embed their work in a growing literature and address audiences beyond an immediate group of informed insiders. While various features have been studied, which document this shift in argument styles, surprisingly little attention has been given to the changes in a key element of academic writing: metadiscourse nouns.

Nouns are overwhelmingly the most frequent word class in English (Biber et al, 1999) and among the various roles they perform in academic writing are conceptual shells (Schmid, 2000), discoursal organisers (Flowerdew, 2003; Flowerdew \& Forest, 2015), academic evaluations (Charles, 2007), or what Jiang and Hyland (2016) refer to as metadiscursive nouns. These are nouns such as fact, analysis and belief which enable writers to organise their arguments and express a stance towards them. In this study, we examine the changing use of metadiscursive nouns over the past 50 years in a corpus of journal articles from four disciplines. Specifically we seek to answer the following questions:

1. Has the use of metadiscursive nouns increased over time?

2. Which pattern of metadiscursive nouns has become more frequent?

3. What changes, if any, have occurred in the functions of metadiscursive nouns?

4. Have these changes been consistent across the four disciplines? 
Before presenting our results, we discuss the characteristics of metadiscursive nouns and spell out their functions, categories, and grammatical patterns.

\section{Metadiscursive nouns: the interpersonal shaping of discourse}

Metadiscourse concerns the ways writers organise their texts to help readers interpret, evaluate and react to propositional content. Hyland (2005: 37) describes it as "the cover term for the self-reflective expressions used to negotiate interactional meanings in a text”. For Jiang and Hyland (2016), metadiscursive nouns contribute to these meanings by marking the organisation of the discourse or the readers' understanding of it. They are a sub-set of abstract nouns and distinguished from them by their unspecific semantic meaning. While the meaning of an abstract noun (such as society or democracy) is constant across contexts, metadiscursive nouns have both this constant meaning and a variable, pragmatic meaning which depends on the local environment.

This potential variability allows writers to point to material in the current context and shape how the reader responds to it, permitting these nouns to function metadiscursively. The importance of these nouns is that they facilitate the organisation of cohesive discourse while allowing writers to express viewpoints on content and interact with readers as members of a particular community. These roles can be seen here ${ }^{1}$ :

(1) Awareness of strategy use was enhanced by the requirement that students should regularly keep language-learning diaries...

(Applied linguistics, 1990)

(2) An interpretation is that a complex economic system gives rise to settled communities.

(Sociology, 1990)

\footnotetext{
1 All examples are from our corpus discussed in section 4. Here, metadiscursive nouns are bolded, the content of realisation is underlined and demonstratives relating to metadiscursive nouns are italicised.
} 
(3) However, their PAA representations are the same or very similar. The representations are numeric. This shortcoming can be eliminated by generalizing the concept and introducing a granular version of the PAA.

(Electrical engineering, 2015)

(4) This is a rather strange reason to discount the study since environmental variation in natural systems is likely to be far greater.

(Biology, 2015)

"Requirement", "interpretation", "shortcoming" and "reason" are metadiscursive nouns and their meaning is more clearly specified by immediate reference. Thus it is unclear what "requirement" and "interpretation" refer to in (1) and (2) until they are specified cataphorically in the subsequent complementing clauses, while "shortcoming" and "reason" in (3) and (4) are specified anaphorically in the previous stretch of discourse.

Flowerdew and Forest (2015) also note this complementary relationship between a metadiscursive noun and what Winter (1992) calls a "lexical realisation" (p. 153). As shown in these examples, the lexical realisation is typically a clause. This provides the content necessary to specify the meaning of the metadiscursive noun while the metadiscursive noun indicates how the realisation is meant to be understood. The metadiscursive noun thus links text with additional information, and this helps writers to move ideas along cohesively and take a position towards it while assisting readers to gain a better understanding of the information. These examples also exhibit the four most frequent lexico-grammatical patterns in which metadiscursive nouns are used, that is, $N+$ post-nominal clause $;+$ be + complementing clause; Demonstrative $+N$; This $+b e+N$ respectively (Schmid, 2000).

These types of unspecific abstract nouns have been found to be very frequent in academic discourse (Charles, 2007; Flowerdew \& Forest, 2015; Gardner \& Davies, 2013) and so have attracted considerable attention, albeit under a range of different 
names. For Halliday and Hasan (1976) they are general nouns, for Ivanič (1991) carrier nouns, for Francis (1986) anaphoric nouns, for Tadros (1985) advance labels, for Hinkel (2001) enumerative and resultative nouns, for Flowerdew and Forest (2015) signaling nouns and for Schmid (2000) they are shell nouns. As many of these labels suggest, however, authors have mainly been concerned with the discourse-organizing, cohesive functions of these nouns (see Benitez-Castro \& Thompson, 2015, for a critical review of the literature). With the exception of Charles (2007) and Jiang \& Hyland (2015), their stance-making role has been almost entirely unexplored. By drawing on Hyland's (2005) influential model of metadiscourse, Jiang and Hyland (2016) emphasise that metadiscursive nouns perform both interactive and interactional metadiscourse functions. Interactive metadiscourse concerns the writer's awareness of readers and the need to structure the text to their expectations and requirements while the interactional dimension addresses the ways writers step into their texts to comment on their message and involve readers (Hyland, 2005).

In the interactive dimension, then, metadiscursive nouns signal the relationships between parts of the text so that readers will recover the writer's preferred interpretations and goals. The nouns either point backward, to encapsulate earlier material into the ongoing discourse, or forward to anticipate forthcoming information. They work to signal the relationships between parts of the text and address the management of information flow. This interactive function reveals a writer's awareness of a participating audience and the ways the text must accommodate its probable knowledge, rhetorical expectations and processing abilities. The writer's purpose here is "to shape and constrain a text to meet the needs of particular readers, setting out arguments so that they will recover the writer's preferred interpretations and goals" (Hyland, 2005, p. 49). 
Metadiscursive nouns also have interactional stance-making functions (Jiang \& Hyland, 2015; Charles, 2007) where writers intrude to comment on their message (Hyland, 2005). They are essentially evaluative and engaging rather than cohesive, helping to convey a writer's perspective on the content the noun refers to. For example, in sentence (2), "interpretation" is used as an alternative to, say, "fact" or "evidence" to label the subsequent proposition as a personal view rather than established fact. Similarly, the writer in (3) chose "shortcoming" to offer a negative evaluation of the PAA representations described in prior sentences. The writer's goal here is "to make his or her views explicit and to involve readers by allowing them to respond to the unfolding text" (Hyland, 2005, p. 49). This is the writer's projection of community and exhibits the ways he or she conveys judgments, aligns with readers and responds to an imagined dialogue with them.

Metadiscursive nouns are interesting rhetorical devices as they are able to perform these two functions simultaneously. The options available to writers using metadiscursive nouns have been described by Jiang and Hyland $(2015,2016)$ and are presented in Table 1. This shows that metadiscursive nouns express how academic writers mark entities, describe attributes of entities and discuss the relations between entities. 
Table 1 Expressive classification of metadiscursive nouns

\begin{tabular}{|c|c|c|}
\hline Entity & Description & Examples \\
\hline text & concretizable metatext & report, paper, extract \\
\hline evidential & $\begin{array}{l}\text { events, processes, } \\
\text { evidential cases }\end{array}$ & $\begin{array}{l}\text { change, process, } \\
\text { observation }\end{array}$ \\
\hline discourse & verbal propositions and & argument, claim, \\
\hline & speech acts & conclusion \\
\hline \multirow[t]{2}{*}{ cognition } & cognitive beliefs and & decision, idea, belief, \\
\hline & attitudes & $d o u b t$ \\
\hline Attribute & Description & Examples \\
\hline quality & $\begin{array}{l}\text { traits that are admired or } \\
\text { depreciated }\end{array}$ & $\begin{array}{l}\text { advantage, difficulty, } \\
\text { value }\end{array}$ \\
\hline manner & circumstances of actions & time, method, way, extent \\
\hline & and state of affairs & \\
\hline \multirow[t]{2}{*}{ status } & epistemic, deontic and & possibility, trend, choice, \\
\hline & dynamic modality & ability \\
\hline Relation & Description & Examples \\
\hline $\begin{array}{l}\text { cause-effect, } \\
\text { difference, etc. }\end{array}$ & $\begin{array}{l}\text { cause-effect, difference, } \\
\text { relevance }\end{array}$ & reason, result, difference \\
\hline
\end{tabular}

Nouns which characterise entities do so by either conveying writers' judgement of texts, events, discourses or aspects of cognition. Those representing texts refer to a segment of writing, another text or a concrete piece of research, with examples such as report, paper and study being typical. Evidential nouns refer to either actions or evidential cases, with examples such as change, case, observation and finding being frequent. Discourse nouns describe verbal propositions and speech acts, such as argument, claim and conclusion while Cognition nouns concern beliefs, attitudes and elements of mental reasoning, such as decision, idea, notion and aim.

Nouns relating to attributes evaluate the quality, status or formation of entities. Thus nouns pertaining to quality assess whether something is admired or criticised, valued or disparaged. Here assessments are made on plus or minus scale (e.g. good-bad; 
important-unimportant), typically involving nouns such as advantage, difficulty and failure. Nouns relating to manner describe the circumstances and establishment of actions and states of affairs. Nouns such as time, method, way and extent depict either their connection to place and time, the way in which they are carried out or the frequency with which they occur. Metadiscursive nouns which concern status express judgments of epistemic, deontic and dynamic modality. Epistemic modality concerns possibility and certainty such as likelihood and truth; deontic modality bears on obligation and necessity (e.g. need and obligation); dynamic modality describes ability, opportunity and tendency (e.g. ability, potential and tendency).

Finally, nouns encode how a writer understands the connection between the information in a proposition, conveying relations such as reason, result and difference (Jiang \& Hyland, 2015, 2016).

This function-based classification of metadiscursive nouns offers us a way to categorize the possible perspectives that writers take in their texts, bringing into focus how they encode subject matter, research processes, and evaluations, all of which are central aspects of intellectual work (Hyland, 2009). Metadiscursive nouns are therefore an important extension to metadiscourse (Hyland, 2017) and have been found to exhibit variations across disciplines (Jiang, 2017b), genres (Liu \& Deng, 2017) and writer proficiency levels (Işık-Taş, 2018).

\section{Corpora and methods}

To trace changes of language features in research articles over the past 50 years we created three corpora, taking research articles from the same five journals in four disciplines spaced evenly at 25-year intervals over 50 years: 1965, 1990 and 2015 . The fact that journals come and go, that they undergo topic splitting and specialisation, and that they are replaced by new ones over time places some constraints on diachronic 
research, but we sought to select robust journals at the top of their respective fields (as defined by the Thompson-Reuters categories) and with a long history.

We selected journals from disciplines which offered a cross-section of academic practice, representing soft and hard sciences: applied linguistics, sociology, electrical engineering and biology. From each of these four fields we took six papers at random from each of the five journals which had achieved the top ranking according to their 5year impact factor in 2015. The journals are listed in Appendix 1. Two journals, TESOL Quarterly and Foreign Language Annals, began only in 1967 and so papers were chosen from issues in that year. Single and co-authored papers were chosen in equal numbers. Overall, the corpus comprises 30 articles from each discipline from each year, 360 papers of 2.2 million words (Table 2), showing a massive increase in the length of articles over the period:

Table 2 Corpora by discipline and word length

\begin{tabular}{lcccc}
\hline \multicolumn{1}{c}{ Discipline } & $\mathbf{1 9 6 5}$ & $\mathbf{1 9 9 0}$ & $\mathbf{2 0 1 5}$ & Change (\%) \\
\hline Applied linguistics & 110,832 & 145,712 & 237,452 & $\mathbf{1 1 4 . 2}$ \\
\hline Biology & 244,706 & 240,255 & 237,998 & $\mathbf{- 2 . 7}$ \\
\hline Elec engineering & 92,062 & 124,631 & 235,681 & $\mathbf{1 5 6 . 0}$ \\
\hline Sociology & 149,788 & 205,238 & 262,203 & $\mathbf{7 5 . 0}$ \\
\hline Totals & $\mathbf{5 9 7 , 3 8 8}$ & $\mathbf{7 1 5 , 8 3 6}$ & $\mathbf{9 7 3 , 3 3 4}$ & $\mathbf{6 2 . 9}$ \\
\hline
\end{tabular}

As mentioned above, Schmid (2000) argues that the most common lexico-grammatical patterns with nouns are $N+$ post-nominal clause, Demonstrative $+N, N+$ be + complementing clause, and This + be $+N$. Jiang (2017a) offers a more delicate analysis and shows that, in published research articles, $N$ that clauses and $N$ to-infinitive clauses are the most typical of the $N+$ post-nominal clause pattern and this $N$ is the most frequent within Demonstrative $+N$ pattern. We part of speech tagged the corpora using TagAnt (Anthony, 2015) and then used the concordance software AntConc (Anthony, 2019) to search for $N$ that, $N$ to-infinitive, this $N, N+$ be + complementing and This + 
$b e+N$ clauses. Following this, we conducted a manual scan of the concordance lines to improve the accuracy of the parsing and exclude cases the programme had identified which were not functioning metadiscursively (according to the definitions above).

Both authors worked independently on a 10\% sample of cases of each search item and achieved an inter-rater agreement of $97 \%$ on grammatical patterns, $96 \%$ on metadiscursive functions and $95 \%$ on functional categorisation. We resolved disagreements and then normalised the results to 10,000 words to allow comparison across the corpora. Log likelihood tests were conducted to determine whether an identified difference in frequency is statistically significant.

\section{Overall changes in use of metadiscursive nouns}

We identified 1,840 metadiscursive nouns in the 2015 corpus, averaging 18.9 cases per 10,000 words. This was a rise of $118 \%$ since 1965 and remains a significant increase of $34 \%(\log$ likelihood $=50.3, p<0.001)$ even after adjusting for the large increase in length of papers. We can say with some confidence, then, that writers have embraced metadiscursive nouns in their interactional repertoire and are increasingly investing in them to strengthen the accessibility and persuasiveness of their academic arguments (Hyland \& Jiang, 2018a, 2018b).

Hyland and Jiang (2019) see this trend as

a rational response to changing contexts in which interdisciplinary research and the need to talk to external funders, commercial sponsors and other non-specialists is becoming more important (p. 228).

Therefore, it is a professional imperative to ensure not only that one's arguments are comprehensible, but also compelling. As shown in these examples below, metadiscursive nouns contribute to this rhetorical end in research writing by clearly 
signalling connections between ideas, framing points of view and supporting interpretations.

(5) Fuzzy clustering methods consist in soft dividing a set of objects into clusters in a way that the members of the same cluster are more similar to each other than to the members of the other clusters. This idea has been introduced by Ruspini and used by Dunn to construct a fuzzy clustering method based on the criterion function minimization. One of the most popular clustering methods based on this approach is the fuzzy Formulameans (FCM) method introduced by Bezdek [2].

(EE, 2015)

(6) My primary aim is to reveal the main characteristics of this persistent opposition, rather than to overcome, in one way or another, the problems between them. This descriptive approach is fully intentional. (Soc, 2015)

\section{Changes in lexico-grammatical patterns}

Further analysis of the concordances shows that this $N$ pattern is most frequent across the 50-year span and records the most significant increase, of 37.4\%. Other patterns achieving a remarkable increase are $N$ be clause and $N+$ post-nominal clauses. This be $N$ pattern remains at a low level of use. Table 3 presents these diachronic changes.

Table 3 Changes in metadiscursive noun patterning (per 10000 words)

\begin{tabular}{|c|c|c|c|c|c|}
\hline & $\mathbf{1 9 6 5}$ & $\mathbf{1 9 9 0}$ & $\mathbf{2 0 1 5}$ & Log likelihood & $\boldsymbol{p}$ \\
\hline this N & 8.4 & 11.5 & 11.6 & 36.4 & $<0.001$ \\
\hline N be clause & 3.8 & 3.8 & 4.9 & 10.2 & $<0.005$ \\
\hline N + nominal & 1.5 & 1.8 & 2.1 & 8.0 & $<0.005$ \\
\hline this be N & 0.4 & 0.4 & 0.3 & 1.9 & 0.2 \\
\hline Total & $\mathbf{1 4 . 1}$ & $\mathbf{1 7 . 5}$ & $\mathbf{1 8 . 9}$ & $\mathbf{5 0 . 3}$ & $<\mathbf{0 . 0 0 1}$ \\
\hline
\end{tabular}


Compared with the other structures, this $N$ pattern provides academic writers with a useful means of encapsulating information and incorporating it into the ongoing discourse. In (7) and (8), for example, the metadiscursive nouns procedure and shortcoming build an interpretative frame for how readers should understand the previous message, essentially telling them what the statement means and aligning their thinking with the author's own. It thus guides reader interpretations and ensures these match the writer's intentions.

(7) For each cell and each task epoch separately, we grouped all spikes emitted in the interval $[0.001,1]$ s post-feedback and randomly assigned each of them to a trial (repeated 1,000 times, Fig 5a). This procedure is equivalent to drawing the number of spikes ...

(8) These studies leave unclear, however, how repression affects those with a weak identity because accounts of activists only contain people committed to the cause. We can address this shortcoming because we do not have an activist-specific sample.

(Soc, 2015)

Another reason for the growing popularity of the this $N$ pattern structure is that it has the advantage of allowing writers to achieve this interactive goal succinctly. In one short structure writers can capture how they see something and convey this to readers clearly. With academics overwhelmed by a massively expanding literature, they are often reading for bottom line results of relevance to their own research, making conciseness and precision now highly valued. This is clear in the stylistic advice given to submitting authors on journal websites:

A manuscript should be written in concise and sufficiently nontechnical language to be intelligible both to general biologists and to specialists in other fields. (Quarterly Review of Biology) ${ }^{2}$.

\footnotetext{
2 Instructions for authors given by The Quarterly Review of Biology, retrieved at https://www.journals.uchicago.edu/journals/qrb/instruct?mobileUi=0
} 
Your readers, like you, are busy and want to find the relevant information quickly and efficiently. To improve the readability of your writing, use short sentences. This can be achieved by presenting only one idea per sentence and limiting the sentence length to a maximum of 20-25 words. (Springer Nature) $)^{3}$.

Although Liu and Deng (2017) found the $N$ be clause pattern to be more frequent in popular science magazines than research articles, we identified a substantial rise in this pattern in our corpora. Jiang (2017a) observes that metadiscursive nouns that characterise propositional information serve as the subjects of clauses and are presented as given information. What this means is that readers are more likely to accept the evaluation as valid. Examples (9) and (10) give us a flavour of this rhetorical effect.

(9) in this time of unprecedented forced displacement, a pressing challenge is to strengthen teachers' capacities to serve the needs of English language learners who either are in conflict situations or have lived through them...

$(\mathrm{AL}, 2015)$

(10) One possibility is that SvkA accumulation near the spindle may serve to concentrate this protein at the midbody for its subsequent role during cytokinesis.

Academic writers are therefore increasingly inclined to exploit this pattern to emphasise the importance of their claims and highlight their stance, constructing an effective interactional appeal to a more diverse audience, ensuring that readers with less specialised knowledge still get the take-home message.

\footnotetext{
${ }^{3}$ Instructions for authors by SpringerNature, retrieved at https://www.springernature.com/gp/authors/campaigns/writing-in-english/writing-in-english-concise-language
} 
Rising by $40 \%$ from a low base in $1965, N+$ post-nominal clause pattern is another powerful persuasive device which enables writers to build an inclusive relationship with readers. It does this by foregrounding a writer's assessment of the reliability of what follows and indicating to readers how the material should be understood:

(11) .... a sufficient condition for establishing whether the computed upper bound $\mu_{\mathrm{II}}$ is tight, which is also necessary under the assumptions that $\Phi$ is compact and $\Theta(\varphi)$ is compact for all $\varphi \in \Phi . \quad$ (EE, 2015)

(12) At this juncture, assessing the risks meant assessing the chances that the privileged orders could still impose their status quo. (Soc, 2015) Similar to the $N$ be clause pattern, the $N+$ post-nominal clause offers writers an effective way to front-load their attitude, making their position clear in order to more effectively influence a less predictable readership (Gil-Salom \& Soler-Monreal, 2014).

We also found that changes in the lexico-grammatical patterns were not uniform across the disciplines (Table 4). We note, for example, that this be $N$ pattern increased while this $N$ pattern decreased in the two applied disciplines (applied linguistics and electrical engineering). 
Table 4 Disciplinary changes in metadiscursive noun patterns (per 10000 words)

\begin{tabular}{|c|c|c|c|c|c|c|}
\hline & \multicolumn{3}{|c|}{ Applied Linguistics } & \multicolumn{3}{|c|}{ Sociology } \\
\hline & 1965 & 1990 & 2015 & 1965 & 1990 & 2015 \\
\hline $\mathrm{N}+$ nominal & 1.4 & 1.8 & 3.5 & 2.3 & 3.3 & 3.7 \\
\hline This $\mathrm{N}$ & 12.8 & 12.6 & 12.1 & 8.5 & 11.3 & 12.6 \\
\hline $\mathrm{N}$ be clause & 2.8 & 3.0 & 5.1 & 5.9 & 3.1 & 2.8 \\
\hline This be $\mathrm{N}$ & 0.8 & 1.1 & 1.2 & 0.6 & 0.5 & 0.3 \\
\hline \multirow[t]{3}{*}{ Total } & 17.9 & 18.5 & 22.0 & 17.2 & 18.2 & 19.4 \\
\hline & \multicolumn{3}{|c|}{ Biology } & \multicolumn{3}{|c|}{ Engineering } \\
\hline & 1965 & 1990 & 2015 & 1965 & 1990 & 2015 \\
\hline $\mathrm{N}+$ nominal & 1.2 & 1.1 & 1.0 & 0.9 & 0.8 & 0.6 \\
\hline This N & 8.1 & 9.0 & 10.8 & 14.6 & 12.8 & 11.0 \\
\hline $\mathrm{N}$ be clause & 2.1 & 2.7 & 3.3 & 6.2 & 6.3 & 6.4 \\
\hline This be $\mathrm{N}$ & 0.2 & 0.2 & 0.1 & 0.3 & 0.4 & 0.7 \\
\hline Total & 11.6 & 13.0 & 15.2 & 21.9 & 20.3 & 18.8 \\
\hline
\end{tabular}

Swales (2005) points out that demonstrative this with an attending noun encapsulates prior discourse and turns it into a generalized proposition. Such generalizations are particularly useful to writers in applied fields as they correspond to the ways these disciplines typically construct knowledge. As Becher and Trowler (2001, p. 177) point out, fields which value the utilitarian application of knowledge seek to present information in ways which allow it "to be spread across a wide front rather than clustered round a limited number of problems". Our results, then, show applied fields taking greater advantage of the this be $N$ pattern to build a smooth flow of information and, more importantly, establish textual coherence by signalling clearly the writer's intended meaning:

(13) The data from the interviews illustrate that all four teachers were aware of the need to engage with vocabulary in the reading lesson and to 
pay specific attention to guessing or deducing meaning from context. This is a particularly important strategy for test contexts. (AL, 2015)

(14) Carbon nanotubes, graphene, and dichalcogenides are examples of materials whose specific properties tied to the electron transport in an atomic-sized layer thickness are found exceptional for potential electronic usage. This is an interesting argument...

(EE, 2015)

Another change worth noting in Table 4 is the increased use of $N+$ post-nominal clause pattern in the soft disciplines and its decline in the hard sciences. This is less straightforward to explain, but speculatively it may point to the different preferences of these disciplines in how they discuss the world. As Hyland and Tse (2005) show, the hard fields tend to prefer verbal predicates, especially those reporting research activities. This practice reflects a principal scientific tenet which emphasises the explanatory value of experimental results, as here:

(15) we definitely prove that ascllb is repressed, while nkx6.1 is maintained, by Notch signaling in both the dorsal and ventral buds.

(Bio, 2015)

(16) These results demonstrate that usually FCPM-IRLS performs better than the other classifiers.

(EE, 2015)

The diachronic analysis shows, however, that the soft domains favour the power of discursive persuasion offered by the use of noun forms:

(17) it is perhaps for the reason that these L1 studies also present equivocal findings.

$(\mathrm{AL}, 2015)$

(18) At a more general level, the importance of legitimacy is rooted in the assertion that revolution is fundamentally a contest of ideologies.

(Soc, 2015) 
The use of $N$ be clause increased in all disciplines except sociology. It was typically used to introduce either the aim of the study (19), point out the difficulties encountered (20), or the reliability of an interpretation (21).

(19) The aim of the present study was to investigate the reception and comprehension of English used for the specific purpose of advertising (i.e., EBP), in Poland, an EFL country.

(20) a primary challenge is to understand the link between epileptic seizures and additional body parameters: movement, breathing, heart rate, and others.

(21) An interesting possibility is that yolk androgens influence the way food value influences aggression, producing a between-individual by within-individual multidimensional reaction norm. $\quad$ (Bio, 2015)

The sociology concordances, however, showed no neat pattern of functions such as these. The sharp decline in the use of this structure by sociologists suggests that writers in this discipline are moving to alternative ways of claim-making, drawing on other linguistic resources, such as self-mention, to achieve the same purpose. The use of first person to announce research objectives has actually increased over the same period, indicating a more overt authorial presence in announcing claims:

(22) In this study, we aim to explore how women navigate through a gendered drug culture, and how femininities ...

(Soc, 2015)

\section{Changes of metadiscursive functions}

Metadiscursive nouns, as we have noted, serve both interactive and interactional functions in academic texts, organising cohesive discourse and conveying authorial stance. These rhetorical roles are particularly important in today's scholarly publishing culture which is increasingly characterised by a more diverse readership and greater co- 
authorship. These factors make it imperative that readers are able to follow the text and take the same perspective as the writer on the issues it contains.

The interactive dimension involves guiding readers through the argument by constructing both anaphoric and cataphoric references to material (23) and (24).

(23) Given the directionality and power of selection, this suggests that the appearance of cells might be inevitable in any planet similar to earth, with oceans and tectonic activity generating a constant flux of solutions out of redox equilibrium, organic building blocks, and a repeated turnover of mineral surfaces. This viewpoint also has profound implications for empirical research into the origin of life. (Bio, 2015)

(24) The justification for this decision was that while any kind of lemmatizing potentially impacts on gaining a full understanding of collocational behaviour, the impact of not lemmatizing is arguably greater because it considerably reduces ... (AL, 2015)

Table 5 shows that anaphoric and cataphoric reference increased by a similar extent (about 34\%) although anaphoric references greatly exceed cataphoric.

Table 5 Changes of interactive functions of metadiscursive nouns (per 10000 words)

\begin{tabular}{|r|c|c|c|c|c|}
\hline & $\mathbf{1 9 6 5}$ & $\mathbf{1 9 9 0}$ & $\mathbf{2 0 1 5}$ & Log likelihood & $\boldsymbol{p}$ \\
\hline Anaphoric reference & 8.9 & 11.9 & 11.9 & 31.78 & $<0.001$ \\
\hline Cataphoric reference & 5.3 & 5.6 & 7.0 & 17.26 & $<0.001$ \\
\hline Total & $\mathbf{1 4 . 1}$ & $\mathbf{1 7 . 5}$ & $\mathbf{1 8 . 9}$ & $\mathbf{5 1 . 2 8}$ & $<\mathbf{0 . 0 0 1}$ \\
\hline
\end{tabular}

The preference for anaphoric forms is a result of the fact that writers are typically seeking to gather up the preceding discourse and use it to move the argument forward. 
They are constantly seeking to align "what has already been said" and current text and “pick up where the previous sentence has left off” (Swales \& Feak, 2005, p.33), making this alignment transparent to the reader. Using the two types in tandem, writers are able to use metadiscursive nouns to point backward and forward in anticipation of readers' changing processing needs as they proceed through their text.

The interactional use of metadiscursive nouns is concerned with the projection of writers' attitudes and judgements, indicating how they understand topics and evaluate the degree of assurance that can be given to material. Table 6 displays the changes in expressive categories of metadiscursive nouns across 50 years. Nouns indicating the writers' stance towards attributes of things were the most common overall. Within this category those referring to manner, describing the circumstances and formation of research activities and affairs, were the most frequent sub-category, accounting for $18.4 \%$ of all metadiscursive nouns. Within the entity category, writers most often took a stance towards evidential cases, describing real-world actions, which comprised $20.5 \%$ of all nouns. Metadiscursive nouns referring to texts and cognition are used least of all.

Table 6 Changes of expressive categories of metadiscursive nouns (per 10000 words)

\begin{tabular}{|r|c|c|c|c|c|}
\hline & $\mathbf{1 9 6 5}$ & $\mathbf{1 9 9 0}$ & $\mathbf{2 0 1 5}$ & Log likelihood & $\boldsymbol{p}$ \\
\hline Entity & $\mathbf{8 . 7}$ & $\mathbf{7 . 7}$ & $\mathbf{8 . 4}$ & 0.39 & $>0.05$ \\
\hline text & 1.2 & 1.1 & 1.0 & 1.36 & $>0.05$ \\
\hline evidential & 4.6 & 3.6 & 3.9 & 4.30 & $<0.05$ \\
\hline discourse & 1.6 & 1.7 & 2.0 & 3.27 & $<0.05$ \\
\hline cognition & 1.3 & 1.3 & 1.5 & 1.05 & $>0.05$ \\
\hline Attribute & $\mathbf{7 . 4}$ & $\mathbf{8 . 4}$ & $\mathbf{8 . 8}$ & 8.91 & $<0.05$ \\
\hline quality & 2.1 & 2.6 & 2.6 & 3.91 & $<0.05$ \\
\hline status & 2.0 & 2.4 & 2.7 & 7.66 & $<0.05$ \\
\hline manner & 3.3 & 3.4 & 3.5 & 0.43 & $>0.05$ \\
\hline Relation & $\mathbf{1 . 2}$ & $\mathbf{1 . 4}$ & $\mathbf{1 . 8}$ & 8.80 & $<0.05$ \\
\hline Totals & $\mathbf{1 7 . 3}$ & $\mathbf{1 7 . 5}$ & $\mathbf{1 9 . 0}$ & $\mathbf{5 . 8 7}$ & $<\mathbf{0 . 0 5}$ \\
\hline
\end{tabular}

There is a rise in the normed frequency in all but two of the eight categories, indicating that writers are increasingly taking the opportunity to use metadiscursive nouns where 
they can. Relation and status nouns show the largest rises over the years, increasing by $50 \%$ and $35 \%$ respectively and coming to play an important role in shaping academic arguments:

(25) One explanation for this difference would be that while zebrafish CACs present pancreatic progenitor activity, mammalian CACs have retained a very limited capacity in vivo...

(Bio, 2015)

(26) One possibility is that this pattern results from the writers' giving more space in their texts to propositions they later disclaim. (AL, 2015)

It is also worth mentioning that entity nouns decreased slightly (by 3.4\%) as a result of a decline in the use of textual (16.7\%) and evidential nouns $(15.2 \%)$. It seems that academic writers are more concerned with evaluating issues and exploring the relations between them than using nominals to define what they are. The examples below indicate something of this difference, with examples such as (27), referring to textual entities, increasingly replaced by those which refer to the manner in which actions are conducted (28).

(27) With more publicity than accompanies an opening night Broadway production, the Surgeon General of the United States released the publication, Smoking and Health, a summary of much of the significant research work thus far done on tobacco's relationship to health. This study was not concerned with the veracity of the findings ... (Soc, 1965)

(28) Scholars of Folk Linguistics have equally made headway in conceptualizing a folk theory of language which can account for the distinct ways that linguists and non-linguists perceive language. $(\mathrm{AL}, 2015)$ 
This change is a possible consequence of the increasing specialization of disciplinary fields and the consequent expansion of published literature. These factors may make the naming of evidential accounts less necessary.

This fall in entity nouns, however, is principally in the hard domains as Table 7 shows. Table 7 Change of functions of metadiscursive nouns by discipline (per 10000 words)

\begin{tabular}{|c|c|c|c|c|c|c|}
\hline & \multicolumn{3}{|c|}{ Applied linguistics } & \multicolumn{3}{c|}{ Sociology } \\
\cline { 2 - 7 } & $\mathbf{1 9 6 5}$ & $\mathbf{1 9 9 0}$ & $\mathbf{2 0 1 5}$ & $\mathbf{1 9 6 5}$ & $\mathbf{1 9 9 0}$ & $\mathbf{2 0 1 5}$ \\
\hline Entity & $\mathbf{6 . 9}$ & $\mathbf{7 . 2}$ & $\mathbf{1 0 . 5}$ & $\mathbf{6 . 5}$ & $\mathbf{7 . 0}$ & $\mathbf{7 . 8}$ \\
\hline objects & 0.6 & 0.6 & 0.7 & 0.7 & 0.7 & 0.8 \\
\hline evidential & 1.8 & 2.5 & 6.0 & 2.9 & 3.1 & 3.5 \\
\hline discourse & 2.1 & 2.0 & 1.8 & 1.4 & 1.6 & 1.7 \\
\hline cognition & 2.4 & 2.1 & 2.0 & 1.5 & 1.6 & 1.8 \\
\hline Attribute & $\mathbf{9 . 2}$ & $\mathbf{9 . 0}$ & $\mathbf{8 . 8}$ & $\mathbf{8 . 8}$ & $\mathbf{9 . 1}$ & $\mathbf{9 . 6}$ \\
\hline quality & 3.0 & 2.4 & 2.0 & 3.2 & 3.0 & 2.6 \\
\hline status & 2.1 & 2.0 & 1.8 & 2.7 & 2.9 & 3.1 \\
\hline manner & 4.1 & 4.6 & 5.0 & 2.9 & 3.2 & 3.9 \\
\hline Relation & $\mathbf{1 . 8}$ & $\mathbf{2 . 0}$ & $\mathbf{2 . 7}$ & $\mathbf{1 . 9}$ & $\mathbf{1 . 9}$ & $\mathbf{2 . 0}$ \\
\hline Totals & $\mathbf{1 7 . 9}$ & $\mathbf{1 8 . 2}$ & $\mathbf{2 2 . 0}$ & $\mathbf{1 7 . 2}$ & $\mathbf{1 8 . 0}$ & $\mathbf{1 9 . 4}$ \\
\hline & & $\mathbf{B i o l o g y}$ & & & Engineering \\
\hline T.9 & $\mathbf{1 9 6 5}$ & $\mathbf{1 9 9 0}$ & $\mathbf{2 0 1 5}$ & $\mathbf{1 9 6 5}$ & $\mathbf{1 9 9 0}$ & $\mathbf{2 0 1 5}$ \\
\hline Entity & $\mathbf{7 . 8}$ & $\mathbf{6 . 8}$ & $\mathbf{7 . 0}$ & $\mathbf{1 3 . 2}$ & $\mathbf{1 0 . 0}$ & $\mathbf{7 . 7}$ \\
\hline textual & 0.5 & 0.6 & 0.5 & 3.0 & 2.6 & 1.9 \\
\hline evidential & 5.8 & 4.0 & 3.2 & 7.7 & 4.8 & 2.7 \\
\hline discourse & 1.0 & 1.5 & 2.3 & 1.7 & 1.8 & 2.0 \\
\hline cognition & 0.5 & 0.7 & 1.0 & 0.8 & 0.8 & 1.1 \\
\hline Attribute & $\mathbf{3 . 5}$ & $\mathbf{6 . 4}$ & $\mathbf{7 . 2}$ & $\mathbf{7 . 8}$ & $\mathbf{8 . 9}$ & $\mathbf{9 . 6}$ \\
\hline quality & 0.7 & 2.4 & 2.7 & 1.6 & 2.6 & 3.1 \\
\hline status & 0.9 & 1.9 & 2.1 & 2.1 & 2.6 & 3.8 \\
\hline manner & 1.9 & 2.1 & 2.4 & 4.1 & 3.7 & 2.7 \\
\hline Totals & $\mathbf{1 1 . 6}$ & $\mathbf{1 3 . 9}$ & $\mathbf{1 5 . 2}$ & $\mathbf{2 1 . 9}$ & $\mathbf{2 0 . 0}$ & $\mathbf{1 8 . 8}$ \\
\hline
\end{tabular}


When taking a position on entities using nouns, writers in the soft disciplines use more evidential types ( $\log$ likelihood $=41.22, p<0.01$ ), giving a view on research processes as viable and evidence as supported by data. This emphasises the perspective they are taking and strengthens support for their claims. The increase in evidential nouns reflects the growing importance of of empirical research "based on evidence from the real world" (Adams et al., 2007, p. 28), especially in applied linguistics which has witnessed a significant move away from more personal accounts of pedagogy over the 50 years. We can see this in (29) and (30) where the writers refer to what they have discussed in the prior discourse as being underlined by real-world observation and evidence. They can then proceed to build academic arguments and strengthen the persuasive ties between segments of discourse on the basis of this:

(29) In keeping with Duff's (2012) observation that critical case studies examine learners in terms of larger social issues related to power, oppression, and discrimination, the broader study sought to investigate the language ideologies embedded in the linguistic practices of the immigrant students and the school...

$(\mathrm{AL}, 2015)$

(30) Also linked to broader mental health issues, Bolton and Oatley (1987) examined the interaction between unemployment, depression and social support networks, finding that people in paid work had greater access to quality social support compared to the unemployed. This evidence is consistent with that found vis-a-vis physical and mental health, suggesting that unemployment has ...

(Soc, 2015)

In the hard science disciplines it is the use of discourse and cognition nouns which has increased markedly ( $\log$ likelihood=10.96, $p<0.001$; log likelihood=5.08, $p<0.05$ ). These metadiscoursal nouns help writers enhance the persuasive force of research findings, as we can see here: 
(31) ICA is based on the assumption that the observations are a linearly mixed set of independent sources/components, an assumption that allows identification of the original sources subject to only scaling and permutation ambiguities...

(32) Proteome comparisons and clustering, showed no detectable evidence that $\mathrm{C}$. glabrata chromosome $\mathrm{C}$ left and right arm proteins come from different phylogenetic origins. In support of this conclusion, mapping of ancestral centromeres by Gordon et al. [37] ... (Bio, 2015)

In disciplines heavily reliant on experimental procedures and inductive logic, reference to reasoning and summarising textual nouns play an important role in guiding readers to the right direction and to the appropriate inferences. With today's scientific papers often directed to those outside the narrow specialism of the paper, such guidance often needs to be explicit, asserting rather than demonstrating.

Within the attribute category, the hard knowledge fields have increased their use of nouns denoting quality ( $\log$ likelihood=39.33, $p<0.001$ ), commenting either on the relative desirability of particular aspects of entities. Such judgements, especially positive evaluations, offer a clear signal to the reader what a writer considers important or worth attending to, thus seeking to gain acceptance for their claims. Below are two extracts in the corpora.

(33) Although the proximity of thaliaceans to ascidians is supported by a number of morphological and molecular arguments, more definitive evidence will be obtained by molecular phylogenetic analyses of nuclear coding sequences. This is the utmost value for the elucidation of the origin and evolution of thaliaceans.

(Bio, 2015) 
(34) A clear advantage of representing control problems using LMIs is that multiple control requirements (design specifications and constraints) are possible by simply appending new LMIs [25]. (EE, 2015)

Manner nouns, on the other hand, have seen an increase in all disciplines except engineering. As (35) and (36) show, manner nouns label actions or describe the circumstance around these actions, thus communicating a clear message about how readers are expected to understand the writer's message.

(35) this will require learners to speak the respective languages in different contexts while keeping an eye on the language of tourism. This approach together with motivation will make them more competent for satisfactory performance ...

$(\mathrm{AL}, 2015)$

(36) In a recently released cottonwood management plan, the preservation of existing stands and the reestablishment of new stands along the Missouri River on retired cropland were proposed. This is a long-awaited condition that could potentially help solve a problem ...

(Bio, 2015)

\section{Final observations and conclusion}

We have described the characteristics and functions of a class of rhetorical items we have called metadiscursive nouns and shown how they have changed in research writing in recent years to become a powerful resource for writers. We have, moreover, argued that far from contributing to the abstract character of academic prose and "suck[ing] the lifeblood from potentially lively prose" as Sword have claimed (2015, p.21), these forms are highly interactive. They offer writers ways to structure cohesive discourse, manage their evaluations of research activities and highlight what they see as important aspects of their argument. Through the use of metadiscursive nouns, 
academics are able to weave a closely-knit map of ideas so that readers can better make sense of argument, and hopefully accept, their propositions. With a diachronic analysis of our parallel corpora, we have also suggested that the rhetorical use of these nouns is responsive to both disciplinary and social changes.

Changes in the research and publication environment, such as those promoting author collaboration, to publish more for career purposes, to achieve greater professional visibility and to reach non-specialist and commercial audiences, seem to have had a serious impact on rhetorical practices (Hyland \& Jiang, 2019). These effects have been observed in the nominal packaging of information through the increased use of noun phrases (Biber \& Gray, 2016), greater nominalisation (Hyland \& Jiang, under review), and the use of nominals in evaluative that clauses (Hyland \& Jiang, 2018c). The growth of metadiscursive nouns also index these changes. We have discovered considerable increases in this $N$ and $N$ be clauses patterns, which reflect writers' growing efforts to strengthen the clarity, accessibility and persuasiveness of their texts to a diverse readership. Likewise, nouns referring to relation and status of entities have shown a remarkable rise as a consequence of writers seeking to establish clear arguments and stress the relationships between their elements.

Our study shows that all four disciplines overwhelmingly prefer the this $N$ pattern because of its usefulness in encapsulating information and incorporating it into the ongoing discourse. Beyond this, however, the disciplines have responded in different ways to changing circumstances, and indeed, have perhaps been affected in different ways. Writers in the social sciences have, of course, felt greater pressures in recent years to research and publish as much as they can to establish their careers. This competition, however, is perhaps felt more intensely by those in the hard sciences, where academics often have the additional expectation to cross disciplinary boundaries and to reach out to new audiences who can make use of their research, often for commercial purposes. 
The soft knowledge disciplines are more inclined to use the $N+$ post-clause pattern while the hard domains prefer $N$ be clauses. The former helps foreground the writer's assessment of the reliability of information and how readers should understand it, while the latter allows writers to present information as accepted and uncontroversial. Both are powerful persuasive devices.

We have also discussed disciplinary variations in the functional work metadiscursive nouns have been asked to do over the last 50 years. It appears that the hard disciplines have increased their use of quality nouns, especially commenting on the value and importance of topics to enhance its value in the eyes of readers who perhaps have less specialised knowledge, especially those on appointment and promotion boards. Writers in the soft domains, on the other hand, now use more evidential nouns to stress empirical support for their propositions. We have suggested this may be a consequence of a growing data-supported scientism in the humanities and social sciences.

In sum, the interactive and interactional use of metadiscursive nouns offers us an insight into how writers understand the different rhetorical contexts in which they work and the kinds of assistance readers might need to follow and accept their arguments. Underlaying our discussion has been the claim that metadiscoursal nouns qualify for special attention from teachers and researchers interested in academic writing, illustrating one way in which scholars talk about the world. Equally, however, we have been making an argument for including these resources in the rhetorical repertoire of metadiscourse and the ways that language choices construct generic, disciplinary and social contexts.

\section{References}

Adams, J., Khan, H. T.A., Raeside, R., \& White, D. (2007). Research methods for graduate business and social science students. London: Response. 
Anthony, L. (2015). TagAnt (Version 1.2.0). Tokyo, Japan: Waseda University. Retrieved from http://www.antlab.sci.waseda.ac.jp/

Anthony, L. (2019). AntConc (Version 3.5.8). Tokyo, Japan: Waseda University. Retrieved from http://www.antlab.sci.waseda.ac.jp/

Atkinson, D. (1999). Scientific discourse in sociohistorical context: The Philosophical transactions of the Royal Society of London, 1675-1975. Mahwah N.J.: Erlbaum Associates.

Becher, T., \& Trowler, P. (2001). Academic tribes and territories: Intellectual enquiry and the culture of disciplines ( $2^{\text {nd }}$ ed.). Philadelphia PA: Open University Press.

Benitez-Castro, M.-A., \& Thompson, P. (2015). Shell-nounhood in academic discourse: A critical state-of-the-art review. International Journal of Corpus Linguistics, 20(3), 378-404.

Biber, D., \& Gray, B. (2016). Grammatical complexity in academic English: Linguistic change in writing. Cambridge: Cambridge University Press.

Biber, D., Johansson, J., Leech, G., Conrad, S., \& Finegan. E. (1999). Longman grammar of spoken and written English. Harlow: Longman.

Charles, M. (2007). Argument or evidence? disciplinary variation in the use of the Noun that pattern in stance construction. English for Specific Purposes, 26(2), $203-218$.

Flowerdew, J. (2003). Signalling nouns in discourse. English for Specific Purposes, $22,329-346$.

Flowerdew, J., \& Forest, R. (2015). Signalling nouns in English: A corpus-based discourse approach. Cambridge: Cambridge University Press.

Gardner, D., \& Davies, M. (2013). A new academic vocabulary list. Applied Linguistics, 35(3), 305-327.

Gil-Salom, L., \& Soler-Monreal, C. (Eds.). (2014). Dialogicity in written specialised genres. Amsterdam: John Benjamins. 
Hinkel, E. (2001). Matters of cohesion in L2 academic texts. Applied Language Learning, 12(2), 111-132.

Hyland, K. (2005). Metadiscourse: Exploring interaction in writing. London: Continuum.

Hyland, K. (2009). Academic discourse: English in a global context. London: Continuum.

Hyland, K. (2017). Metadiscourse: What is it and where is it going? Journal of Pragmatics, 113, 16-29.

Hyland, K., \& Jiang, F. K. (2018a). "In this paper we suggest": changing patterns of disciplinary metadiscourse. English for Specific Purposes, 51, 18-30.

Hyland, K., \& Jiang, F. K. (2018b). Academic lexical bundles: how are they changing? International Journal of Corpus Linguistics, 23(4), 383-407.

Hyland, K., \& Jiang, F. K. (2018c). 'We believe that ...': changes in an Academic Stance Marker. Australian Journal of Linguistics, 38(2), 139-161.

Hyland, K., \& Jiang, F. K. (2019). Academic discourse and global publishing: Disciplinary persuasion in changing times. London: Routledge.

Hyland, K., \& Tse, P. (2005). Evaluative that constructions: signalling stance in research abstracts. Functions of language, 12(1), 39-63.

Jiang, F. K., \& Hyland, K. (2017). Metadiscursive nouns: interaction and cohesion in abstract moves. English for Specific Purposes, 46, 1-14.

Jiang, F. K. (2015). Nominal stance construction in L1 and L2 students' writing. Journal of English for Academic Purposes, 20, 90-102.

Jiang, F. K. (2017a). Metadiscursive nouns in disciplinary writing (Unpublished PhD Thesis). The University of Hong Kong, Hong Kong.

Jiang, F. K. (2017b). Stance and voice in academic writing: The "noun+ that" construction and disciplinary variation. International Journal of Corpus Linguistics, 22(1), 85-106. 
Jiang, F. K., \& Hyland, K. (2015). 'The fact that': stance nouns in disciplinary writing. Discourse studies, 17(5), 529-550.

Jiang, F. K. \& Hyland, K. (2016). Nouns and academic interactions: a neglected feature of metadiscourse. Applied linguistics, advanced access, 1-23.

Iş1k-Taş, E. E. (2018). Nominal stance construction in IELTS tests. Journal of English for Academic Purposes, 34, 1-11. https://doi.org/10.1016/j.jeap.2018.02.004

Liu, Q., \& Deng, L. (2017). A genre-based study of shell-noun use in the $N$ - be-that construction in popular and professional science articles. English for Specific Purposes, 48, 32-43. https://doi.org/10.1016/j.esp.2016.11.002

Schmid, H. J. (2000). English abstract nouns as conceptual shells: From corpus to cognition. Berlin: Mouton de Gruyter.

Swales, J. M. (2005). Attended and unattended "this" in academic writing: a long and unfinished story. ESP Malaysia, 11(1), 1-15.

Swales, J. M \& Feak, C. B. (2005). Academic writing for graduate students: Essential tasks and skills (2nd ed.). Ann Arbor: University of Michigan Press.

Sword, H. (2015). The writer's diet. Auckland: Auckland University Press.

Tadros, A. (1985). Prediction in Text. Birmingham: English Language Research, University of Birmingham.

Winter, E. O. (1992). The notion of unspecific versus specific as one way of analysing the information of a fund-raising letter. In W. C. Mann \& S. A. Thompson (Eds.), Discourse description: Diverse linguistic analyses of a fund-raising text (pp. 131170). Amsterdam: John Benjamins. 
Appendix 1: Journal list

Applied Linguistics

TESOL Quarterly (1967- )

Language Learning (1948- )

Foreign Language Annals (1967- )

Modern Language Journal (1916- )

College Composition and Communication (1950- )

\section{Sociology}

American Journal of Sociology (1895- )

Social problems (1953- )

The British Journal of Sociology (1950- )

American Journal of Economics and Sociology (1941- )

The Sociological Quarterly (1960- )

\section{Biology}

The Quarterly Review of Biology (1926- )

Biological Reviews (1923- )

Radiation Research (1954- )

BioScience (1964- )

The Journal of Experimental Biology (1923 - )

\section{Electrical Engineering}

Proceedings of the IEEE (1963 - )

Automatica (1963 - )

IEEE Transactions on Automatic Control (1963 - )

IEEE Journal of Solid-State Circuits (1966 - )

IEEE Transactions on Information Theory (1963 - ) 